\title{
Social Networks as a Component of Educational Area of the High School
}

\author{
Elena Zhestkova \\ Faculty of preschool and primary \\ education \\ Lobachevsky State University of \\ Nizhny Novgorod (Arzamas \\ Branch). \\ Arzamas, Russia \\ ezhestkova@mail.ru \\ Elvira Maklaeva \\ Faculty of preschool and primary \\ education \\ Lobachevsky State University of \\ Nizhny Novgorod (Arzamas \\ Branch). \\ Arzamas, Russia \\ mak_ela@mail.ru
}

\author{
Dmitriy Gusev \\ Faculty of preschool and primary \\ education \\ Lobachevsky State University of \\ Nizhny Novgorod (Arzamas \\ Branch). \\ Arzamas, Russia \\ dimigus@rambler.ru \\ Svetlana Fedorova \\ Faculty of preschool and primary \\ education \\ Lobachevsky State University of \\ Nizhny Novgorod (Arzamas \\ Branch). \\ Arzamas, Russia \\ sveta fedorov@mail.ru
}

\author{
Natalja Kudakova \\ Faculty of preschool and primary \\ education \\ Lobachevsky State University of \\ Nizhny Novgorod (Arzamas \\ Branch). \\ Arzamas, Russia \\ kkudakova@mail.ru \\ Liudmila Filippova \\ Faculty of preschool and primary \\ education \\ Lobachevsky State University of \\ Nizhny Novgorod (Arzamas \\ Branch). \\ Arzamas, Russia \\ lyda0968@bk.ru
}

Abstract - Currently, there is an active process of expanding the educational space, including the higher education of the Russian Federation, at the expense of informatization. Informatization of educational area of higher education is

impossible without using web-technologies and, such as social networks.

The authors of the article suggest social networks to be understood as a working version of an "interactive multiuser website that implements a network social structure consisting of a group of nodes - social objects (groups of people, communities) and links between them (social relationships), on the basis of which participants can establish relationship with each other.

Currently, there are several main functions of social networks: educational; adaptive (acts as a resource of adaptation); compensatory (replacing institutional mechanisms of adaptation); informational (supports communication between authors of social interaction); transit (allows an individual to make the transition along the social ladder); coordination; social support functions (strengthen communication within and outside the network) and the function of a sociocultural marker.

Social networks, speaking as a special social space of the Internet, have become the sphere in which traditional forms of socialization and social relations are transformed, and communication as a type of leisure activity becomes possible not in the traditional form of direct live communication, but acquires the features of simple communication.

The authors state that at present using social networks in the educational area of the higher school of the Russian Federation is minimal. The network educational community on the basis of a social network - a virtual educational environment - is necessary, first of all, for students who have difficulties in communicating directly or need additional knowledge and skills that an educational institution cannot provide. From the point of view of education, social networks can be: freely available (non-specialized networks for which professional communities are not paramount and purely professional communities of practice) and in a corporate format (free-access networks; not specialized ("general profile" network)).

The advent of Web 2.0 has expanded the possibilities of using social networks in education, has changed the attitude to the Internet as a whole, and teachers have begun to more actively use the Internet services for educational and educational purposes, in extracurricular activities and creative activities.

It has already been experimentally proven that network communities can serve as pedagogical practices for development: co-thinking, tolerance, mastering decentralized models, critical thinking.

Keywords - High school, informatization, social networks, web-technologies.

\section{INTRODUCTION}

Currently, there is an active process of expanding education area, including higher education of the Russian Federation, due to informatization. "The term" informatization has become generally accepted and spread in all spheres of society. Under it today they understand both politics, and processes, and technologies, and mechanisms [1].

Informatization of educational area of the higher education without using of web technologies and, such as social network.

In modern native literature, despite of the presence of publications, which reveal the essence and describe the content of already used information educational technologies, works dedicated to social networks as an information educational web-technology, obviously not enough. Therefore, the purpose of this article is to disclose essence of the concept and phenomenon of 
social networks and their using in educational area. Its main tasks were: identifying keeping the concepts of "networks" and "social networks", studying of social networks as educational technology and resource for development (personality, group, vocational school, etc.), studying of the dynamics of social networks and their using in education [2], [3].

The works on the analysis and popularization of concrete experience in the using of social networks in education have already appeared in literature. For example, in the work "The development of social networks and their integration into the system of education in Russia", the authors consider the genesis, development and modern various interpretations of the concept of "social network", describe the most popular social networks of Russia (Vkontakte, Odnoklassniki, Facebook, Twitter) and the problems of their using in educational procession. Summarizing several definitions, the authors propose to understand that social network is a working version of "interactive multiplayer website that implements a network social structure consisting of a group nodes social objects (groups of people, communities) and links between them (social relations), on the basis of which participants can establish relationship with each other [4, p. 475].

According to A.S. Duzhnikova, the site may be called a social network when it is possible to create individual profiles (name, status, interests, etc.); user interaction (through browsing each other's profiles, internal mail, comments, etc.); achieving joint goals through cooperation (for example, finding new friends, group blogging, etc.); sharing of resources (for example, information); meet the needs through the accumulation of resources [5, p. 240].

Noting the author's sociological approach and considering it incomplete we consider the functionality of social networks as a web-technology; and such distinctive features as "the creation of personal products by a file in which you often need to provide real personal data and information about yourself (place of study and work, hobbies, life principles, etc.); providing a full range of opportunities for the exchange of information (sharing photos, videos, placing text records (in the blogs or micro blogs), the organization of thematic communities, the exchange of personal messaging, etc.); ability to set and maintain a list of others users (for example, friendship, kinship, business and work relationships, etc.).

Currently, there are several basic functions of social networks: educational; adaptive (acts as a resource of adaptation); compensatory (replacing institutional mechanisms of adaptation); information (support communication between the authors of the social actions); transit (allows an individual to make the transition through social ladder); coordination; social support functions (strengthened connections inside and outside the network) and the function of sociocultural marker. Social networks, speaking as a special social space of the Internet that became the sphere in which the traditional forms of socialization and social relations, and communication as a type of leisure activity it becomes possible for a person not in the traditional form of direct living communication, but acquires the features of simple communication: in a network a person can to be what he wants to appear, but he is not. According to analytical company Strategy Analytics, in the next five years, various about 1 billion people will use social sites. Currently using social networks in the educational area of higher education of the Russian Federation is a minimum. Apparently, network educational resource will unite teachers, students, programmers, methodologists. It is a complex and multifaceted task. Network social networking community - virtual education environment is necessary, first of all, for students who have difficulties communication in direct communication or in need of additional knowledge and skills that the school cannot provide.

Actualize the problem of using social networks in education area of the higher school of the Russian Federation allows running experience of their application [6], [7].

In particular, it shows that social networks have functional scrap, which allows you to share information quickly, discuss important problems, create collaborative learning content. Using social networks, they master new means and ways of communicating with other people all over the world, recognize each other's interests, learn to effectively search and analysis of information [8]. Thanks to the experience of using social networks for solving educational and research tasks, changes convert students into a resource as solely entertaining understanding of its powerful uses in professional activities.

The possibility of interaction between students and teachers in the network in a convenient time ensures the continuity of the educational process and the possibility of detail-planning of educational and research work of students (tasks and consultations every day). It allows students who miss lessons, take part online. It is possible for teachers to conduct classroom lectures in interactive mode [9]. A virtual classroom created in a social network can be accessible to students and parents everywhere via the mobile Internet. You can show uploaded videos, discussions.

The presentations that begin in classroom can be continued in a social setting. It allows students to spend more time in active learning through discussion. When students create their social profile they indicate different details about their personality: views, interests, favorite music, movies and books, favorite quotes, etc. Teachers have an opportunity to learn more about the student's personality, his individual features [10].

\section{General Regulations}

With the emergence of a large number of new social services and networks, teachers and students have wide opportunities to use them in the educational process. These web services and networks are gradually becoming the social and information environment within which you can solve many of the pedagogical tasks of new 
educational standards that require using of radically new methods and forms of education.

As is known, the interest in social networks among young people in modern society is becoming one of the main features of the 21 st century. Most of the life of modern youth goes on-line. That is why using the Internet and social networks so popular among young people is becoming a very important tool for increasing the efficiency of the educational process, a way to create an interactive educational environment and a reliable means of communication between teachers and students. In this regard, an active search is being carried out for the possibilities of applying social networks in the teaching and educational area of the university, taking into account the needs of modern student youth [11].

According to research, the most relevant social networks in Russia are Odnoklassniki, VKontakte, Moi Mir and others. Moreover, VKontakte is the most popular social resource for the student community, and it can be considered as an educational resource in organizing educational activities of students [12].

The communication of the teacher with the students with the help of this interactive resource makes them equal participants in the communication process, the communication process itself becomes more interesting, operational and efficient, and its goal is clearer and more realistic. In addition, as practice shows, the fact that the teacher is an active and experienced user of this interactive resource increases interest in him as an individual and teacher, encourages communicating and cooperating with him and, as a result, significantly affects the psychological climate of the educational process and its effectiveness [13].

In organizational terms, using of social networks in the educational process of a university creates opportunities for:

1. Organizations of individual, collective and group work of students. The combination of group and individual forms of work contributes to a better understanding and assimilation of educational material. The advantage of using social networks is that there is the possibility of a collective assessment of the results and processes of work. An indisputable fact is that with the help of social networks you can build a student's individual educational route and use it as a space for organizing students' independent work and for distance learning.

2. Organization of educational and extracurricular activities. The possibility of holding various contests, presentations, videos using social services and networks can help the teacher in his work, if it is used as information medium in which information about various events will be placed.

3. Organization of project activities of students. Social networks can become a platform for creating individual and network projects, which will allow participants to implement their projects, gain knowledge from practitioners, find like-minded people and the necessary resources, and gain motivation for further self- development.

The ability to attach text documents, images, video and audio recordings to VKontakte messages is another important advantage. Working with students in a created group allows you to centrally post information in the news feed, upload documents, video, audio, photographic materials, where students can watch video lectures, subject films, video tutorials on various subjects of primary school, listen to lectures by leading teachers and psychologists, as well as music that can be used for educational purposes [14], [15].

Lobacevsky State University of Nizhny Novgorod (Arzamas Branch) has accumulated experience of using the VKontakte social network in order to organize students' independent work when studying methodological disciplines [16]. This work is used as a supplement to classroom studies in the study of pedagogical and methodological disciplines, such as "Universal educational activities and technologies of their formation", "Theory and technologies for the development of mathematical representations of children", "Theory and technologies of teaching mathematics", etc.

Since the first training session, the orientation of the student audience to interaction in social networks begins. The teacher tells how to find his page on the social network and how the group will work together. It is explained that this group will systematically place the necessary educational material - lecture materials, tasks for performing extracurricular independent work, etc. In addition, a specific time is specified in advance that the teacher is willing to devote to communicating with students and answering their questions. Thus, this group is a social-educational environment that allows a group of people to communicate, in our case, students and teachers united by a common interest [17], [18], [19].

Interactive communication of the teacher with students and students among themselves is carried out in the following areas:

- placement of lecture materials in the social network, as well as text, video and audio materials aimed at expanding and deepening the knowledge gained during the classroom (for example, video tutorials posted at https://www.youtube.com, https: / /videouroki.net);

- implementing of tasks for independent work (search and processing of information, preparation of project tasks, messages, reports, discussion and correction of which are carried out quickly and efficiently);

- editing by the teacher of materials prepared by students, discussing them online, both with the teacher and among themselves, which significantly reduces the preparation time;

- individual tasks for students with the ability to monitor their implementation and additional counseling during extra-curricular time, which, respectively, significantly saves classroom time;

- joint work of students on creative projects with the 
possibility of getting online advice from the teacher;

- the ability to control the self-study activities of students who, due to illness or for some other reason, do not attend classes, which allows them to prevent a significant lag in students from the curriculum and to flexibly regulate the course of the educational process;

- application of the presented material in the group allows all participants to independently or jointly create online learning content (glossaries, articles, discussions, multimedia libraries, etc.),

- solving organizational issues, etc. [20], [21], [22].

The experience of using such a group makes it possible to highlight the following benefits: students, communicating in an informal setting, have the opportunity to gain new knowledge, leading to a more effective development of the discipline; the student and the teacher, interacting in the social network, behave more freely, which allows the student to ask questions about the discipline without fear of critical assessment from the teacher and classmates; the student has the ability to communicate online not only with the teacher, but also with his classmates, which makes it possible to organize conferences and dialogues, especially before the session; the teacher for the student becomes a member of the social network, that is, the interaction at the vertical level is replaced by the interaction at the horizontal level and this inspires confidence on the part of the student and improves the process of mastering the material; the teacher has the opportunity to quickly inform students about upcoming plans [23].

Thus, using social networks in pedagogical activity ensures the continuity of the educational process, stimulates students' independent cognitive activity, and contributes to the improvement of the skills of comprehensive assessment and comparison of the information received; ensures the continuity of the educational process; enables students to build an individual educational trajectory.

\section{RESULTS AND DISCUSSION}

The scientific laboratory of didactics of the rural school of Lobachevsky State University of Nizhny Novgorod (Arzamas Branch) is working to identify effective ways of organizing educational activities with using ICT by future and current teachers of rural schools. One of the innovative scientific projects of the laboratory is a model of network interaction of teachers of rural schools in the implementation of the pedagogical potential of folk applied creativity, aimed at studying the possibilities of using ICT in the implementation of artistic and aesthetic education and spiritual and moral development of rural students by means of folk applied creativity [24], [25].

The project is developed on the basis of the social network "creative teachers Network" (Innovative Teachers Network) - an Internet portal for communities of teachers working in secondary education and using or planning to use ICT in the learning process. The largest teacher Internet project in Russia the educational Internet is the resource of Federal importance, it is intended for network interaction of teachers in order to implement new technologies in the organization of the educational process [26], [27].

The organization of work on the network communication of teachers can be presented in the form of a Community of teachers of rural schools "from folk crafts - to the moral ideals of cultural heritage", which will be another web site of the network of creative teachers. Its activities will focus on:

- the development and support of new technologies in the organization of the educational process of rural schools;

- exchange of advanced pedagogical experience;

- the preservation and development of Russian folk culture;

- creating a database of author's materials prepared on the basis of ICT for the organization of work for the student and the teacher of rural school on arts and crafts.

A holistic view of the structure and sections of the main web page of the community of teachers of rural schools "from folk crafts-to the moral ideals of cultural heritage" is given in the form of a model in Fig. 1.

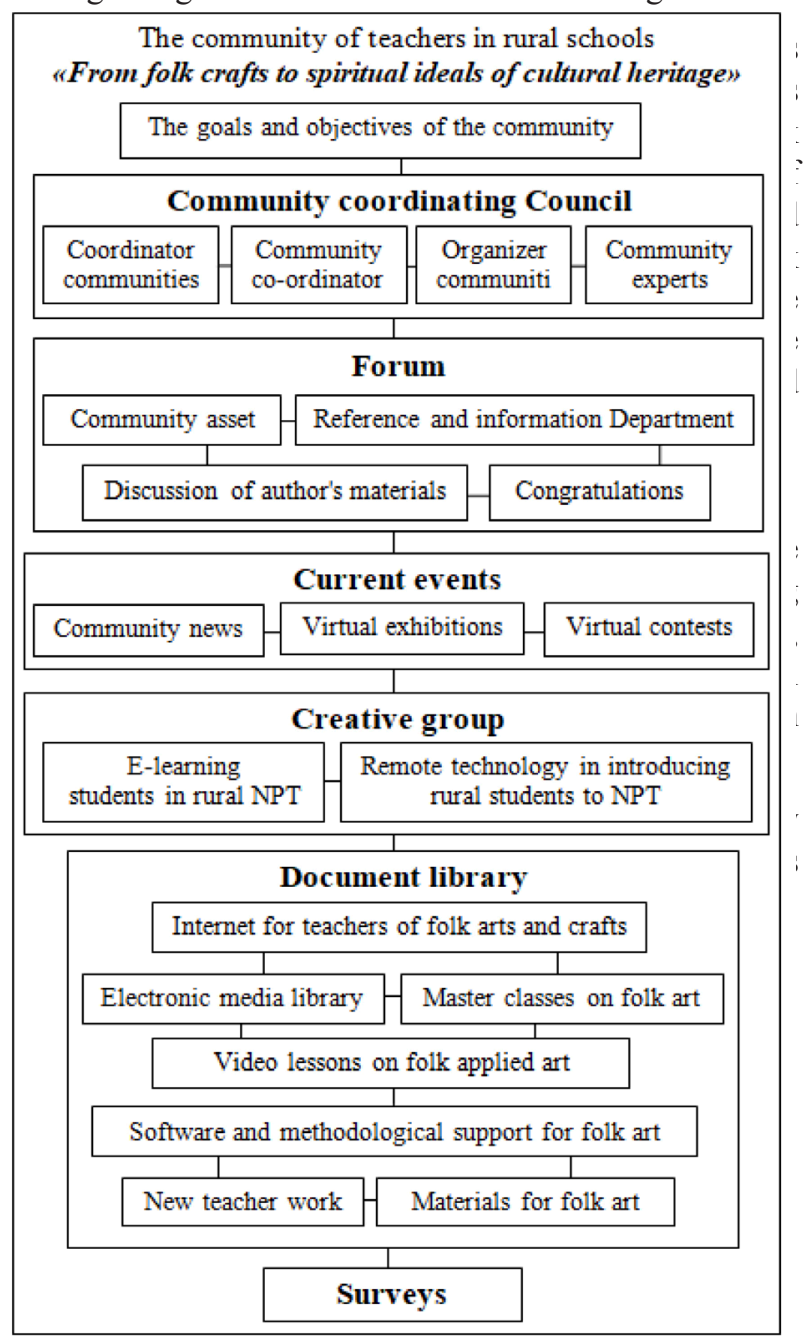

Fig. 1. Model of network interaction of teachers of rural schools in realization of pedagogical potential of national applied creativity 
(NPT)

\section{CONCLUSION}

First of all, the clarity of the ideology and interface of social networks of the majority of the Internet audience saves time by passing the students' adaptation to the new communicative space. Placing information in a social network a person not only indicates the range of his professional interests, but also informing additional information, non-verbally invites interested people to his surroundings.

The network educational community based on the social network is a virtual educational environment that allows students not only to carry out vertical communication, but also to gain knowledge, share them, draw logical conclusions, share their reasoning with others.

Networking communities allow students and teachers to form groups for more in-depth study of the material, create models together, replicate ideas, and develop joint thinking. Proper using a social network by the teacher allows you to intuitively feel the audience being trained and select a suitable training platform and tools for it.

Social networks make it possible not only to transfer information in a mobile way and exchange data, but also to conduct various kinds of sociological surveys that provide the basis for monitoring issues of any social strata.

The possibility of constant interaction of students and teachers in the network at a convenient time for them ensures the continuity of the educational process, there is an opportunity for a more detailed organization of work individually with each of the students. In addition, discussions, dialogues, started during the classroom, can be continued in the social network, which allows students to spend more time in the process of discussing educational issues, which provides a more thorough development of the material and the active position of the student in the learning process. Information support of the educational site in the social network allows students, who have missed a lesson not to drop out of the educational process, take part in discussions and complete tasks from home.

Of course, social networks are not the main means of network education, but their ability to solve educational problems today is underestimated by the professional community.

\section{REFERENCES}

[1] S.A. Atroshchenko and S.V. Napalkov, The use of thematic educational Web-quest in the development of cognitive independence of students. Web-technologies in the educational space: problems, approaches, prospects: a collection of articles of the participants of the International Scientific and Practical Conference; Arzamas branch of UNN. N. Novgorod: LLC «Raster$\mathrm{NN} », 2015$.

[2] E.A. Zhestkova, Subject information and educational environment formation of information and communication competence of future professionals: Environment. Technology. Resources: Proceedings of the 11th International Scientific and Practical Conference, june 15-17, 2017, vol. II. Rezekne: Rezekne Academy of Technologies,
2017, pp. 180-186.

[3] S.V. Fedorova, and E.V. Maklaeva, "Ways of organizing the reflective activity of younger schoolchildren in the implementation of educational projects," Problems of modern pedagogical education. Ser.: Pedagogy and Psychology, vol. 57, Part 1, pp. 239245, 2017.

[4] G.A. Vorobiev, Technology web quests in the teaching of foreign languages and cultures: Theoretical and experimental linguodidactics: Coll. scientific articles. Pyatigorsk: PSLU, 2003.

[5] E.N. Voronova, "Organization of independent educational activities of students as a factor in improving the quality of the pedagogical process," Language and world of the studied language, vol. 1, pp. $125-127,2011$.

[6] O.G. Miller, "Web quest in teaching students," Proceedings of the Southern Federal University. Technical science, vol. 111, No. 10, 2010. [Access mode] Available: http://cyberleninka/article/n/vebkvest-v-obuchenii-studentov\#ixzz3N03bptTr.

[7] E.S. Poleshchuk, "Web quest as a way of organizing students' search and research activities in teaching a foreign language," Personality, family and society: issues of pedagogy and psychology, vol. 44, pp. 34-37, 2014.

[8] E.R. Dikikh, On the use of social networks in education: Personality, family and society: issues of pedagogy and psychology: Sat. Art. on mater. XVI Intern. scientific-practical conf. Part I, Novosibirsk: SibAK, 2012.

[9] O.A. Klimenko, Social networks as a means of learning and interaction of participants in the educational process: Theory and practice of education in the modern world: materials of the Intern. scientific conf. (St. Petersburg, February 2012), SPb.: Renome, 2012. pp. 405-407, Available: https://moluch.ru/conf/ped/archive/ 21/1799/ [Access April, 3, 2019].

[10] A.A. Dragunova, "Educational Internet resources as a means of forming professional foreign language communicative competence of students," Yaroslavl Pedagogical Journal, vol. 1, pp. 163-165, 2013.

[11] L.V. Rusina, The modern science: 2013, Budapest. [Access mode] Available: http://scaspee.com/contacts.html.

[12] B. Dodge, Some thoughts about Web Quests, 1995, [Online] Available: [Access mode] http://webquest.sdsu.edu/about_ webquests. html

[13] T. March, "Are we there yet? A parable on the educational effectiveness of technology," Multimedia Schools Magazine, vol. 7(3), pp. 54-55, 2000. [Access mode]. Available: www.infotoday. com/MMSchools/may00/march.htm.

[14] E. Zhestkova, E. Minaeva, N. Ivanova, O. Kolesova, and N. Lapin, Teachers from different countries: Revista ESPACIOS, vol. 38(25), 2017. Page 8. [Access mode] Available: http://www. revistaespacios.com/a17v38n25/17382508.html.

[15] E. Zhestkova, E. Safekiova, N. Ivanova, T. Luchina, and E. Minaeva, "Specifics of Educational Activity Anti-motivation in Future Teachers Subject to the Training Period International," Review of Management and Marketing, vol. 3, pp. 265-259, 2016.

[16] S.V. Fedorova, and E.V. Maklaeva, "Technological aspects of the development of critical thinking of students in teaching mathematics," Modern problems of science and education, vol. 4, 2015. Available: http://science-education.ru/ru/article/ view?id=21125 [Access May, 3, 2019].

[17] E.A. Zhestkova, Problematic approach to the study of literary disciplines in a pedagogical university: Society. Integration. Education. Proceedings of the International Scientific Conference, may 27-28, 2016, Rezekne: Rezeknes Academy of Technologies, 2016. pp. 286-299.

[18] E.V. Maklaeva, and S.V. Fedorova, "Test technologies in teaching students of pedagogical universities," Elementary School, vol. 12, pp. 11-15, 2016.

[19] L.V. Filippova, "Project technologies in teaching of philological disciplines," Volga Scientific Herald Arzamas Pedagogical Readings, vol. 8(36), Part 2, Izhevsk, pp. 44-48, 2014.

[20] E. Zhestkova, E. Gubanichina, S. Oparina, V. Sidorskaya, and D. Gusev, Interactive technologies as a means of forming general cultural and professional competencies among students of a pedagogical university: Society. Integration. Education: Proceedings of the International Scientific Conference, vol. I, may 26-27, 2017, Rezekne: Rezeknes Academy of Technologies, 2017, pp. $454-469$.

[21] N.S. Kudakova, Media education of younger schoolchildren: 
Media and information literacy of a modern teacher: at 3 pm Part 1. Materials of the All-Russian Scientific and Practical Conference. Orenburg, Orenburg State Pedagogical University, october 30-31, 2018, Orenburg: Publishing house "Orenburg book", 2018, pp. 167-171.

[22] N. Kudakova, E. Gubanihina, E. Klyueva, T. Naumova, and E. Zhestkova, The pedagogical potential of information and communication technologies in the formation of ethnic and cultural awareness of younger schoolchildren: Vide. Tehnologija. Resursi Environment, Technology, Resources 11. Cep. «Environment. Technology. Resources - Proceedings of the 11th International Scientific and Practical Conference», 2017. pp. 36-41.

[23] L.V. Filippova, Using active teaching methods in the teaching of the course "Theory and technology of speech development of children," Modern high technologies, vol. 12-3, pp. 561-564, 2015.

[24] E.M. Shulgina and M.A. Bovtenko, "The didactic potential of the web quest technology in the formation of foreign language communicative competence of students of non-linguistic tourist departments," Language and Culture, vol. 1, pp. 76-84, 2013.

[25] J.G. Laborda, "Using Educational Technology \& Society", vol.12 (1), pp. 258-270, 2009.

[26] D. Gusev, E. Zhestkova, N. Kudakova, L. Filippova, and F. Podshednaya, Pedagogical potential of folk-applied creativity by means of ICT in the process of formation of educational and cognitive interest of younger students: Society. Integration. Education. Proceedings of the International Scientific Conference, May 26-27, 2017, Rezekne: Rezeknes Academy of Technologies, 2017, vol. II, pp. 93-108.

[27] D. Gusev, S. Aksenov. R. Arifulina, T. Belyaeva, E. Ilaltdinova, and I. Lebedeva, "In the search of national ideal of russian pedagogue," Journal of Entrepreneurship Education, vol. 3, 2017. 